\title{
LA ILUSTRE FREGONA
}

"Nihil est toto, quod perstet, in orbe"

(Ovidio, Metamorfosis)

A don Luis A. Arocena

Por sus «episodios, lances y sucesos..., tan vívidos y realistas", sus variados y "verosímiles... retratos costumbristas"; su riqueza de materia folklórica, popular: anécdotas, cuentos, chistes, pullas; su música y canciones, coplas y seguidillas... de "ritmos alegres", bailes de "movimientos ágiles", todo "transveberado" de "colores gayos y luminosos", de "una luz radiante", reflejos del «optimismo del autor" ' -entre otros muchos atributos admirables-, La ilustre fregona siempre ha sido apreciada como una de las mejores "Novelas ejemplares" de Cervantes. Sin embargo, casi siempre tales alabanzas vienen condicionadas por reparos críticos respecto a las acciones desarticuladas, "perjudiciales para la unidad de la trama" - la obra interesaría, sobre todo, por el encanto de las 'escenas individuales' ${ }^{2}$; ; respecto al desenlace tan arbitrario, "contrived"; inverosímil 3; a la gran ambigüedad del tema fundamental; al "propósito moralizador" que "no aparece por parte alguna", pese a todas las protestas de ejemplaridad por parte de Cervantes: «las peripecias y recursos moralísticos... no tienen nada de edificantew; de hecho, "diríase de Cervantes que quiso premiar el fruto de su pecado ...Cuando más..., se habría propuesto ejemplificar la preocupación o creencia muy común

1 Gonzalez de Amezú y Mayo, Cervantes creador de la novela corta española, Madrid, C.S.I.C., 1958, vol. 2, 284-5, 309-10.

2 W. C. AtKInSON, "Cervantes, el Pinciano, and the Novelas ejemplares, Hispanic Review, 16, 1948, 208. 358-372.

J. MEw, "The Novels of Cervantesw, Gentlemen's Magazine, sept. 1878, 
en su tiempo y, por extremo grata a él, a saber, el valor anímico de la sangre noble, diferente en todo de la plebeya y villana" 4.

En los estudios más recientes, de perspectivas metodológicas muy distintas, se encuentran muy perspicaces observaciones sobre aspectos fundamentales de La ilustre fregona, pero nos parece que en ninguno de ellos se articula una respuesta satisfactoria, convincente a esos reparos y dudas. En efecto, a veces éstos se reconfirman. Se justifica así un nuevo intento exegético, que a continuación se emprende con una reconsideración de algunas facetas fundamentales de la trama, de los personajes, de las perspectivas narrativas, de la variedad estilística y tonal de La ilustre fregona.

A los trece, Carriazo «se desgarró... de casa de sus padres y se fue por ese mundo adelanten, a cada paso aprendiendo picardías con tanto gusto y "tan bien" que pronto "pudiera leer cátedra en la Facultad al famoso de Alfarachew, y graduándose por fin "de maestro" en ellas en las almadrabas de Zahara, "finibusterre de la picaresca", donde "está en su centro el trabajo junto con la poltronería... sin disfraz el vicio..., el juego siempre, las pendencias por momentos, las muertes por puntos, las pullas a cada paso, los bailes como en bodas...n, donde i«campea la libertad"! (922) ${ }^{5}$. Vida de "gran dulzura" para Carriazo en las almadrabas, en que «se da buen tiempo" y en que deja «la mitad de su alma" cuando de ellas sale momentáneamente (922). «A todos los mayores" placeres: cazas, convites, pasatiempos, juegos que se le ofrecian en su noble y rica familia y que "se usan" en aquella ciudad [Burgos], «anteponía el que había recibido en las almadrabas». Por esto, "en ellas tenía de continuo puesta la imaginación" deseando ir de nuevo allá cuanto antes (923). El rutinario «buen tratamiento", con que sus padres quieren hacerle admirable, honrado caballero cortesano, que a Carriazo impacienta, aburre, sofoca, es, en efecto, lo que al fin lo "cansa", empujándolo a «la vida libre», que de inmediato encuentra no sólo preferible sino ideal: "no echaba de menos la abundancia de la casa de su padre, ni el andar a pie le cansaba, ni el frío le ofendía, ni el calor le enfadaba, para él todos los tiempos del año le eran dulce y templada primavera; tan bien dormía en parvas como en colchones: con tanto gusto se soterraba en un pajar de un mesón como si se acostara entre dos sábanas de Holanda" (922). Hasta las incomodidades y miserias de esa "vida andariega" se vuelven

\footnotetext{
4 González de Amezó y Mayo, Cervantes creador de la novela corta española, 285.

5 Citamos por la edición de A. Valbuena Prat, Obras completas de Cervantes, Madrid, Aguilar, 1965. Tras las citas de La ilustre fregona se indica la página entre paréntesis; tras las citas de otras obras también el título.
} 
en placer por la embriagadora sensación que le produce a $\mathrm{Ca}$ rriazo la exención de todos eos deberes, responsabilidades, restricciones, preocupaciones impuestas, ¡la completa «libertad" personal!

Teniendo bien en cuenta esta aversión íntima de Carriazo a toda dependencia y obligación, se explica como natural también su indiferencia desdeñosa o aprensión respecto a las mujeres (sin contar entre ellas a la pobre Argüello, cuya grotesca fealdad repele a todos los mozos y no sólo a Carriazo) ${ }^{6}$ y su desinterés amoroso hasta por la hermosísima Costanza, siendo así innecesaria la explicación de esta actitud por una supuesta reticencia de Cervantes de entrar en la delicada zona de una posible atracción incestuosa, aunque inconsciente. Con este respecto, basta recordar que en la Entretenida representa la "brumosa" relación, como la llama Castro, de D. Antonio con su hermana ${ }^{7}$. No es, pues, por querer evitar semejante situación, sino más bien por querer destacar esa predisposición anímica de Carriazo que Cervantes hace repetidas referencias a su indiferencia amorosa por Costanza, que así no son, como se suele pensar, artificiosas en absoluto: El "deseo» de Avendaño de ver a Costanza es «enamorado" mientras el de Carriazo es sólo "curioso»; y al verla, "a $\mathrm{Ca}$ rriazo le pareció tan bien como a su compañero, pero enamoróle mucho menos, y tan menos, que quisiera no anochecer en la posada sino partirse" (927-8). ¡Naturalmente! El desdén o la indiferencia de Carriazo por la relación amorosa se determina también, muy sugerentemente, por sus constantes, fervorosos sueños con las almadrabas, único reino, según cree, de la completa libertad; sueños que probablemente no abandona jamás, ni al fin, según lo indica su meramente pasiva aquiescencia en el matrimonio que le arreglan los padres.

Necesidad insaciable de «libertad», pues, que a veces Carriazo satisface, en parte, "andando todo el día por la ciudad a sus anchuras, mirando bobas" (931) y, otras veces, entregándose exuberantemente a cualquier desahogo colectivo de alegría, en particular cuando éste es manifestable también por el ingenio y la

6 J. CASAlduero lo percibe de un modo distinto: "Cervantes no permite que [Carriazo] se degrade" (Sentido y forma de las Novelas ejemplares, Buenos Aires, 1943, 192). Dice el mesonero: «por vida de vosotras [a la Argüello y a la gallega] que no tengáis dares ni tomares con los mozos de casa, que por vosotros se me van todos» (318). La «moral» de los mozos y de Carriazo no es un factor en esto.

7 Ver nuestro estudio "Cervantes frente a Lope», Anales Cervantinos, 1978, 77 y sigs. A. Soons sugiere que para evitar el incesto de Carriazo se le crea un compañero, Avendaño («Three Novelas ejemplares of Cervantes, Diptych Pattern and Spiritual Intention*, Orbis Literarium, 26, 1971, 89. 
libre fantasía, como en el graciosísimo baile de los mozos de mulas y de las fregonas, auténtica celebración ritual de una venerada momentánea «libertad" de todos los quehaceres cotidianos. Con la condición de que los bailarines «bailasen al modo como se canta y baila en las comedias... y que, para que no lo errasen, que hiciesen todo aquello que él dijese cantando, y no otra cosa...», Carriazo, "de presto, fácil y lindo ingenio, con una felicísima corriente, de improviso empezó a cantar: Salga la hermosa Argüello /moza una vez y no más/.../De la mano la arrebate/el que llaman Barrabás/.../salga la más carigorda /en cuerpo y sin delantal/.../Entren, pues todas las ninfas /y los ninfos.../ y bájense a refregar / las manos por esa arena /.../santígüense y den al diablo/ dos higos de su higueral/... /que el baile de la chacona/ encierra la vida bona, etc. Convertido de improvisto en "autor" de un comiquísimo teatro de marionetas, Carriazo las contempla divertido y complacido del poder de su chispeante fantasía: "Todo lo que iba cantando...hicieron al pie de la letra, ellas y ellos; se hacían rajas bailando la turbamulta de los mulantes y fregatrices del baile" (933). Sin embargo, Carriazo no se propone sólo divertirse con su chacona: ("Bulle la risa en el pecho/ de quien baila $y$ de quien toca/ del que mira y del que escucha"), sino también burlarse de la hipocresía de ciertos espectadores: "Cuántas [veces] fue vituperada [la chacona]/ de los mismos que la adoran!". En efecto, acabado el baile, "uno de los muchos embozados que [lo] miraba, dijo, sin quitarse el embozo: ¡Calla, borracho! ¡Calla, cuero! ¡Calla odrina, poeta de viejo, músico falso.», y tras esto, acudieron otros diciendo tantas injurias y muecas, que Carriazo tuvo por bien callar" (933-4). Después de haberse divertido mucho, de seguro, con el espectáculo, los embozados pretenden indignarse en nombre de su "honradez». De su hipocresía, que ellos llaman, sin duda, "prudencia", "discreción", dan clara muestra ya por el hecho de disfrazarse para poder mirar la chacona, como también para ver a Costanza, de cuya belleza están apasionados, pero sin ánimo de declararlo, identificándose, por la "vergüenza" pública que implicaría su afición a una fregona. Carriazo conoce bien a estos hipócritas, pues son probablemente señoritos de su propia clase social ${ }^{8}$.

Que estos episodios. a momentos algo grotescos, están animados por un tono fundamentalmente cómico, lo sugiere también la serenata de un enamorado de Costanza, con que se remata toda esa diversión nocturna («llegó a los oídos de todos ... una

${ }^{8}$ La gracia cómica con que se realiza toda esta escena del baile hace evocar momentos de El retablo de las maravillas y de Pedro de Urdemalas. 
voz de un hombre»). Serenata de engolada y más bien bizarra retórica y erudición ("alegría que se opone/ a las tristezas confusas/ del padre que da a sus hijos /en su vientre sepultura", etc...) y $\tan$ abstrusa que "no hay diablo que la entienda...; miren qué hará Costancica!” Intento de ostentación erudita, revelada como inapropiada, ridícula palabrería, y galardonada del modo más apropiado: «El acabar estos últimos versos y el llegar volando dos medios ladrillos fue todo uno... Asombróse el pobre y dio a correr por aquella cuesta arriba con tanta prisa, que no le alcanzara un galgo. Infeliz estado de los músicos, murciélagos y lechuzos..." (34-5). Desenlace gracioso, muy evocador de varios análogos en la Gatomaquia de Lope.

Las aventuras toledanas de Carriazo tienen el propósito, entre otros, de hacernos imaginar más concretamente su vida pasada en las almadrabas ("como estaba hecho al trato de las almadrabas"), a que antes se alude sólo de modo muy general: "Aquí se canta, allí se reniega, acullá se riñe, acá se juega, y por todo se hurta..." (922). Así, después de la escena de la chacona, otra de un juego de naipes, en que Carriazo entra con el mayor entusiasmo, porque «era de propiedad del azúcar, que jamás gastó menestra" (938) ${ }^{9}$, y en que pierde todo el dinero y también el asno, recuperándolo poco después todo, gracias a los astutos, sofísticos argumentos con que aturde a los otros jugadores, obligándolos a admitirlo de nuevo en el juego ipor lo ya perdido!: «Dijo... que advirtiesen que él solamente había jugado los cuatro cuartos del asno; pero la cola que se la diesen... nunca su intención fue jugar la cola...", ¡Ingeniosa parodia de la argucia engañosa de los pleitos oficiales! Tal impresión se refuerza por la presencia de testigos y "letrados" que expresan opiniones opuestas sobre "el pleiton. Carriazo sustenta su causa de modo particularmente persuasivo, pretendiéndose feroz, cruel matador de gente (y en esto hay otra posible referencia a la "fuerza de la ley"): «soy yo un hombre que me sabré llegar a otro hombre y meterle dos palmos de daga por las tripas sin que se sepa de quien, por dónde o cómo le vino" (938). Sin embargo, no es mera fanfarronada, según Carriazo ya lo demostró en la riña con un aguador,

${ }^{9}$ En sus ediciones de las Novelas ejemplares. H. Sirber y J. B. Avalle-Arce (Cátedra y Castalia, respectivamenye) of recen interpretaciones cuestionables de este refrán italiano. G. GIUSTI, Raccolta di proverbi toscani, Palermo, Edikronos, 1981, 270: "Zucchero non guastó mai vivanda; zucchero e acqua rosa, non guastó mai alcuna cosa; Accennano a quella dolcezza di modi la quale esprime bontà veraw. Con aplicación graciosamente irónica de este refrán, Cervantes destaca la prontitud de Carriazo en «hacer cuarto» en el juego, del que, evidentemente, piensa salir ganando. 
a quien «arremetió..., y asiéndole con ambas manos por la garganta dió con él en el suelo y tal dolpe dió con la cabeza sobre una piedra, que se le abrió por dos partes" (930). Contrariado de cualquier modo, Carriazo sabe vengarse sin escrúpulo ni miramiento caballeresco alguno. Todo esto hace pensar que no es la pérdida del asno y del dinero lo que le trastorna tanto, sino el hecho mismo de haber perdido, pareciendo así menos listo que sus rivales, humillado. $Y$ en efecto, poco después, al ganar, devuelve el dinero al perdedor y reparte todo lo que le queda "con los circunstantes». Esta "extraña liberalidad pasmó a todos», pero, por lo que se ha sugerido, resulta por completo comprensible como expresión espontánea del desbordante placer por la disipación de todas las percibidas dudas en su renombre de macho y jugador. Al volver a la ciudad "con grande acompañamiento" de aguadores y mozos de mulas, quienes, «si fueran [otros] tiempos, ..., le alzaran por [su] rey» (939), Carriazo siente el júbilo del triunfo y de la fama como debió de sentirla Amadís de vuelta de sus más arduas batallas. Psicológicamente consistente con esta exaltación por el triunfo en el juego, es la honda depresión que Carriazo manifiesta después, al verse motejado por el pueblo con la demanda de la cola. El retrato de Carriazo resulta mucho más complejo e interesante, al percibirse estas variaciones temperamentales $\mathrm{y}$, entre ellas, cierta desconfianza íntima o inseguridad personal, pese a todas sus muchas experiencias mundanales. Así, al decidirse Avendaño a irse a las almadrabas con Carriazo, éste "quedó sobre modo contento..., por parecerle que había ganado un testigo de abono que calificase su baja determinación» (923). Y es probablemente por esta razón, mucho más que por la amistad, que Carriazo, impacientándose tanto por seguir el camino a las almadrabas, no obstante se queda mucho tiempo con Avendaño en Toledo. Por cierto, esta estancia se le hace más tolerable también por su afán, en parte gratificado, de encontrar en Toledo ocasiones comparables a las ya saboreadas en las almadrabas.

La función de Avendaño en la novela deja a menudo muy perplejos a los lectores. A veces se le considera como un «desdoblamiento", otras, como un "contraste" de Carriazo ${ }^{10}$ : mientras éste tendría interés sólo en el mundo picaresco de las almadrabas, aquél lo tendría sólo en el mundo ideal del amor platónico. No nos resulta tan categórica esta diferenciación; requiere cuando menos ciertas calificaciones:

10 Casalduero, Sentido y forma de las novelas ejemplares, 191; J. RodríguezLuIs, Novedad y ejemplo de las novelas de Cervantes, Madrid, J. Porrúa Turanzas, 1980, vol. I, 150. 
La decisión inmediata de Avendaño "de irse... a gozar un verano de aquella felicísima vida" de las almadrabas, después de haber oído las alabanzas que de ella hizo Carriazo, se debe, evidentemente, a la elocuencia persuasiva de éste ("pintósela de modo que...n, 923), pero también, al menos en parte, a las circunstancias de su vida diaria, de seguro muy semejante a la de Carriazo, y, en parte, probablemente, a las fastidiosas tareas escolares de la Universidad de Salamanca, adonde quieren enviarle sus padres "de allí a dos meses». Allí ya había estado "tres años... estudiando las lenguas griega y latina..., por su gusto" (923): ¿Gratificación sólo intelectual? Una considerable experiencia de las consuetudinarias picardías estudiantiles se hace adivinar al demostrarse Avendaño,sin haber estado en las almadrabas, tan ducho como Carriazo mismo en mentir y engañar descaradamente a sus padres: "mostráronse los hijos humildes y obedientes...; nuestra hidalga intención», etc.; en «juntar" o "robar todo el dinero que pudiesen para la huida" (923-4); en disfrazar su identidad con toda clase de mentiras y cuentos: "Tan buen color dió Avendaño a su mentira, que a la cuenta del huésped pasó por verdad»(926) ". Hasta en su carta amorosa a Costanza modifica algún tanto la verdad, o cuando menos la cronología: «A la fama de vuestra hermosura..., dejé mi patria, mudé vestido..." (937). A ciertas picardías amorosas, probablemente cuando estudiante en Salamanca, se refiere él mismo: «aquel amor vulgar con que a otras he querido" (932). Hay, pues, muchas indicaciones de que Avendaño no es una víctima inocente, arrastrada del camino recto por un mal compañero ${ }^{12}$, sino un cómplice ardoroso en la huída y en todas las trampas perpetuadas y proyectadas.

Avendaño atribuye su amor por Costanza al "destino" que "con oculta fuerza" lo "inclina" a ello (932), y el lector recuerda, divertido, que ese "destino" se identifica con las comiquísimas alabanzas, entreveradas de trillado vocabulario floral y vegetal, literario y rústico, que dos mozos de mulas hacen a la bella y esquiva fregona: «Es dura como un mármol, y zahareña como villana de Sayago, y áspera como una ortiga, pero tiene una cara de pascua y un rostro de buen año; en una mejilla tiene el sol, y en otra la luna; la una es hecha de rosas y la otra de claveles, y en entrambas hay también azucenas y jazmines... jes joya para un arcipreste o para un conde!» Esta "relación" de los dos mozos

11 J. HeRRERO, «Emerging realism: Love and Cash in La ilustre fregona», en From Dante to García Márquez. Studies in Romance Literatures and Linguistics, Williams College, 1987, 54-5.

12 Casalduero, Sentido y forma de las novelas ejemplares, 200: «Avendaño se ha dejado arrastrar por la tentadora palabra del amigow. 
de mulas le despiertan a Avendaño "un intenso deseo de verla" (925). Ya está enamorado, ¡de oídas! En realidad, su amor por Costanza se condiciona e intensifica de continuo por las opiniones y actitudes admirativas ajenas, en particular, la de sus rivales: "lo que me trae alcanzado de paciencia es saber que el hijo del corregidor, que es mozo brioso y algo atrevido, muere por ella y la solicita con músicas me parte el corazón la dura saeta de los celos" (931). Al ver a Costanza por primera vez, Avendaño piensa que "todas cuantas alabanzas que le había dado el mozo de mulas eran cortas". En su "rostro" le "parecía ver... lo que suelen pintar de los ángeles", y en toda su presencia un irresistible encanto, que el autor hace apreciar también al lector, por medio de una bella descripción, con algunos detalles de muy delicada sensualidad: «una gargantilla de estrellas de azabache sobre un pedazo de una columna de alabastro: que no era menos blanca su garganta...; zapatos... colorados, con unas calzas que no se le parecían sino por cuanto por un perfil mostraban también ser coloradas...; pendíanle de las orejas dos calabacillas de vidrio, que parecían perlas; los mismos cabellos le servían de garbín y de tocas" ${ }^{13}$. Extraordinaria hermosura, que a Avendaño deja «suspenso y atónito..., lleno de turbación y sobresalto" (925, 927-8), pero que tan sólo puede admirar a distancia, muy raras veces, porque Costanza casi todo el tiempo reza y labra en su cuarto y ka ninguno da lugar de mirarla, cuanto más de ponerse a pláticas con ellan (936). El único intento que él hace de acercársele lo rechaza ella tajantemente: "puesto que una vez tuvo lugar de llegar a hablarla, y viéndolo ella, le habían dicho antes que llegase: ...no tengo necesidad de tus palabras ni de tus oraciones (939). En tales circunstancias, Avendaño no puede aprender nada -si es que se lo ha propuesto- del quilate espiritual, del alma de Costanza, aunque mantenga que la "virtud", el "recogimiento" de ésta lo trae enamorado tanto como su hermosura (932) ${ }^{14}$. Con más probabilidad, el «recogimienton o indiferencia de Costanza aguija siempre más su juvenil vanidad masculina, que, a su vez, hace más avasalladora su pasión amorosa y más obstinada su persecución; que le hace parecer «loco o herejen, por sus hiperbólicas y estrambóticas exaltaciones (931); componer banales coplas amorosas en el libro de cebada - de poeta

${ }^{13}$ El pelo «Salía de castaño y tocaba en rubio» (925). Por no ser «totalmente rubio*, RODRígUEz-LUIS lo atribuye «quizás" al korigen bastardo de la pobre muchachaw (Novedad y ejemplo de las novelas de Cervantes, 145). Nuestra interpretación de la obra rechaza tal simbolismo.

${ }^{14}$ Observa bien J. LOWE: «The angel is a bit surly; the girl's beauty is not reflected in her words" (Cervantes: Two novelas ejemplares, Támesis, 1971, 59). 
tiene escasísimas dotes- (936) y misivas amorosas, disfrazadas de oraciones "para el dolor de muelas" (937); padecer los "recogimientos" de Costanza como eternas "noches lóbregas» (926); $y$, por fin, que le hace prometer toda su "calidad y riqueza" por el amor: "Yo soy un caballero natural de Burgos; si alcalzo de días a mi padre, heredo un mayorazgo de seis mil ducados de renta...; si vos lo quisiéreis ser mío [dueño]..." (937). Avendaño dice que "escondida debajo de aquella rústica corteza" hay una "mina de gran valor y de merecimiento grande», que él persigue con «amor limpio, que no se extiende a más que a servir y a procurar que ella me quiera", lo cual se debe enjuiciar teniendo en cuenta el hecho de que Avendaño, en realidad, no tiene alternativa sino contemplar a Costanza con kamor limpio», a distancia. Por estas y otras razones resulta impropio considerar este amor «ideal», "platónico", en el sentido clásico de una aspiración pura, intensa a la armonía espiritual. "Platónico» lo llama solo Carriazo, mofándose del compañero, quien lo percibe claramente: "ya veo... cuan al descubierto te burlas de mí" (932). El amor de Avendaño no es diferente, en esencia, al de otros enamorados de Costanza: el hijo del corregidor también se le ofrece con cuerpo y alma y toda su hacienda: "Raro, humilde sujeto, que levantas/ a tan excelsa cumbre la belleza/.../las potencias del alma nos encantas/ .../deja el servir, pues debes ser servida/ de cuantos vean tus manos y tus sienes/ resplandecer por cetros y coronas (927); el músico "murciélago y lechuzo", la exhorta: «Fabricad vos vuestra suerteh, ofreciéndole su "más rica» y "más pura voluntad». Hasta algún verso de pretensiones místicas hay: "Cielo empíreo, donde amor / tiene su estancia segura..." (934); el amo de un mozo de mulas piensa quedarse "dos meses en Toledo y en la misma posada, sólo por hartarse de mirarlan; y el mozo de mulas, con gran simpleza, pero de seguro con la misma disposición amorosa, sueña: «En las dos mulas rucias que sabes que tengo mías la dotara de buena gana si me la quisieran dar por mujen (925). Igualmente "platónicos" son, pues, estos enamorados y de seguro también todos esos admiradores embozados que de continuo rondan a la fregona, como polillas nocturnas en frenético revoloteo de una lumbre. Sugestivamente, Carriazo caracteriza de «amorosa pestilencia" (926) la conducta de todos estos enamorados, incluyendo la de su amigo. Sin tal cinismo, diríamos que en el caso de Avendaño se trata sencillamente de un intenso «embelesamiento" juvenil, como lo llama el mismo autor (925), descrito con toques de suma ingeniosidad y gracia artística y desde la pers- 
pectiva fundamentalmente cómica de la obra entera ${ }^{15}$. Y, por fin, se insinúa, de modo insistente, una pregunta: de haber Avendaño ya estado en las almadrabas, como su amigo, ¿se habría detenido tanto tiempo en Toledo, pese a la hermosa fregona?

Otro retrato interesante, pues, pero la función más importante de Avendaño es la de personaje-puente, catalítico: Por medio de su amistad con Carriazo y de su "embelesamiento" por Costanza se nos revelan ciertas características de estos dos - hermanastros, hijos del mismo padre, noble- cuyo contraste constituye, en nuestro juicio, el meollo ideológico de la novela.

Se mantiene que en La ilustre fregona Cervantes sugiere una relación determinista entre el nacimiento o la sangre noble y la excelencia personal ${ }^{16}$. ¿Cervantes? A veces, destaca específicamente que la opinión acerca de las supuestas virtudes del personaje es ajena: "En fin, en Carriazo vió el mundo un pícaro virtuoso, limpio, bien criado y más que medianamente discreto" [subrayado nuestro]. Consecuentemente, desde la misma perspectiva se le contempla a éste en todas las referencias anteriores, que se rematan, precisamente, con el conclusivo En fin: "mostraba ser un príncipe en sus cosas..., bien nacido, porque era generoso y bien partido con sus camaradas", todo lo cual "se descubría... ja tiro de escopeta, en mil señales! [subrayado nuestro] (922). Las graciosas hipérboles precisan la perspectiva popular, algo popuchalera, con que "el mundo", los camaradas enjuician la "alta calidad» de Carriazo. Esta observación es aplicable también a las hipérboles, tan patentemente cómicas, en el notorio episodio de la cola del asno, en que Carriazo, "como bien nacido", le "volvió todo el dinero [al perdedor] y repartió el resto entre los demás: "si fueran los tiempos y las ocasiones de Tamorlán, le alzaran por el rey de los aguadores... [al] gran Lope [Carriazo]» (939). Recuérdese, además, que la extraña "liberalidad» de éste responde probablemente también a impulsos extraños a la genuina generosidad. La perspectiva cómica, ingenua, equivocada o absurda, atribuible al personaje y contemplada con implícita ironía y diversión del autor, aparece con cierta frecuencia en esta novela e incluso, claro está, en la arenga del autor, irónico «consejero", a todos los pícaros: "no os llaméis pícaros si no habeis cursado dos cursos en la academia de la pesca de los atunes», en las almadrabas de Zahara, "allí está... sin disfraz el vicio,

15 Amezó y Mayo dice bien que «No hay novela alguna entre toda la producción cervantina tan regocijada... como La ilustre fregono (Cervantes creador de la novela corta española, 285).

16 Ibid., nota 4. 
etc." (922) ${ }^{17}$. Otras veces, el discurso directo viene mediado por la narración indirecta, como a menudo en la prosa cervantina. Así en este pasaje que importa reproducir: "Los padres dieron documentos a sus hijos de lo que debían hacer y de cómo se habían de gobernar para salir aprovechados en la virtud y en las ciencias que es el punto que todo estudiante debe pretender sacar de sus trabajos y vigilias, principalmente los bien nacidos. Mostráronse los hijos humildes..." (923). Las palabras subrayadas por nosotros son parte de la recomendación paterna, pues así lo sugiere la situación en que se dicen. El contexto episódico y estilístico revela, pues, en todos los casos, que son los personajes mismos, iy no el autor!, quienes relacionan la conducta de $\mathrm{Ca}$ rriazo con la de un "bien nacido" ${ }^{18}$. Por encima de este hecho, muy importante en sí, ¿por qué sería la generosidad, la libertad, la compasión, la discreción..., que se le atribuyen, justa o injustamente, a Carriazo, privativas de una determinada clase social? En las obras cervantinas se demuestra absurda tal contención: Maritornes, Cristóbal de Lugo, Pedro de Urdemalas (quien es también pícaro), para recordar sólo algunos personajes de ínfima clase social, se distinguen por todos estos sentimientos y virtudes; Pedro y Cristóbal con genuina, extraordinaria nobleza de espíritu ${ }^{19}$. En La ilustre fregona, muy significativamente, el mesonero y su mujer prometen encargarse de la criatura sin querer recompensa por ello: "dije que no era menester nada de aquello [los doscientos escudos de oro que les da la peregrina], que no éramos personas que por interés, más que por caridad, nos movíamos a bacer bien cuando se ofrecía». La verdad de esta declaración se pone de relieve con el magnífico detalle de que la mesonera no responde con "palabras de agradecimiento ni de comedimiento alguno" a la peregrina, cuando ésta "le puso en las manos" el bolsillo de escudos. No por desagradecida ni por "simple», sino por el mero hecho de que "estaba suspensa y colgada de la peregrina", es decir, impresionada y conmovida por la penosa situación en que se encuentra la ilustre señora: «le puso en manos" el bolsillo..., "tomó el bolsillo, sin responderle", como casi sin advertirlo (941). El hecho de que el mesonero se manifiesta "alegre sobremanera con el ofrecimiento de los mil escudos» que le hace el padre de Costanza (944) no contradice nues-

17 HerRero, Emerging Realism, 49.

18 En gran parte, por no hacerse esta distinción se ha dificultado tanto la interpretación de la obra en los estudios críticos.

I9 Nuestros estudios: «El gran teatro del mundo y el gran mundo del teatro en Pedro de Urdemalas. Acta neofilológica, 1977; "La caridad jamás imaginada de Cristóbal de Lugow, B.B.M.P., 1980. 
tras sugerencias, pues acepta el dinero sólo como alivio parcial de la separación absolutamente inevitable con Costanza. Mucho menos afectado que su desconsolada mujer, no permanece, sin embargo, frío frente al inminente cambio en su familia, ini mucho menos! "Quince años, un mes y cuatro dias ha que aguardo a quien ha de venir por ella, y la mucha tardanza me ha consumido la esperanza de ver esta venida». ¿Espera el ventero de veras que vengan por Costanza! ¿O más bien, que no vengan?: "Y si en este año... no vienen, tengo determinado de prohijarla y darle toda my hacienda que vale más de seis mil ducados, Dios sea bendito" (942). Bello sueño, compartido con su mujer, fervorosa, intensamente, según lo sugiere también la cuenta precisa que lleva de cada uno de esos años, meses, días que Costanza vive con ellos. El mesonero y su mujer cuidan y quieren a Costanza con conmovedora generosidad y ternura paternal, porque, a todas luces, emocionalmente ya la han prohijado, porque la consideran como hija propia. ¿Se ha observado jamás la relevancia que tiene para esta actitud el hecho de que esta pareja no tiene hijos propios, y de seguro un gran deseo de tenerlos? Son estas circunstancias las que hacen tan triste la separación: "Costanza y la huéspeda se asieron una a otra y comenzaron a hacer tan amargo llanto, que quebraba los corazones de cuantos le escuchaban. Decía la huéspeda: ¿Cómo es esto, hija de mi corazón que te vas y me dejas? ¿Cómo tienes ánimo de dejar a esta madre que con tanto amor te ha cuidado? (946) ${ }^{20}$.

$Y$ hay, por otra parte, personajes cervantinos, nobles de nacimiento, pero flagrantemente mezquinos, ruines, degenerados, sin ninguna calidad espiritual, moral o temperamental redentora, como, por ejemplo, Belica y otros aristócratas, cortesanos y monarcas en Pedro de Urdemalas; Rodolfo en La fuerza de la sangre, para mencionar sólo algunos ${ }^{21}$, y en nuestra novela, muy significativamente, el padre de Carriazo y Costanza, hombre monstruosamente egoísta, violento, cruel chantajista, brutal destructor de la honra y de la vida de una indefensa mujer. Al relatar la violación de ésta, explica que uel silencio, la soledad, la ocasión despertaron en mí un deseo más atrevido que honesto". Se justifica una duda respecto a estas supuestamente imprevistas circunstancias de la visita a la viuda a «la hora de siesta", que suele «llover sueño en [los] criados", por lo cual, precisamente, se puede entrar en la casa, «sin topar con nadie» y subir «hasta el mismo aposento donde ella duerme». El crimen que atribuye a "la suerte»

${ }^{20}$ Se evoca el lamento del padre de Zoraida (D. Quijote, I, cap. 41).

21 Nuestros estudios sobre Pedro de Urdemalas (nota 19); La fuerza de la sangre. Acta neofilológica, 1990; La gitanilla (B.B.M.P., de próxima publicación, 1991). 
que lo "ordenó», ¿no fue, de hecho, meticulosamente premeditado? De cualquier modo, fue de extraordinaria brutalidad y vileza: «subí... a donde ella estaba durmiendo la siesta sobre un estrado negro" - nótese este importante detalle con que se pone de relieve la perdurable congoja de la viuda en luto-, "llegándome a ella la desperté, y teniéndola asida fuertemente, le dije: ...no grite, que las voces que diere serán pregonera de su deshonra... [quedará] en opinión vuestra fama Finalmente, yo la gocé contra su voluntad y a pura fuerza mía; ella cansada, rendida y turbada...; y yo, dejándola como atontada y suspensa me volví a salir». Después de esto, la señora, de seguro sin poder jamás recobrarse de la horrorosa experiencia, "se mudó de aquel lugar a otro», sin que él "jamás la viese» de nuevo, j«ni [que] lo procurasen! (945). De hecho, no hay evidencia alguna de que el violador jamás sintiese arrepentimiento por el crimen cometido ${ }^{22}$. Hasta la referencia a su "deseo más atrevido que honesto" es dudosa como admisión de culpabilidad, pues ¿no lo está quizás justificando por esas circunstancias tan incitantes, "el silencio», "la soledad», "la ocasión»? En efecto, ¿No se manifiesta quizás cierta perversa gratificación lujuriosa hasta en el acto mismo de rememorar el violento acontecimiento: «subí..., el silencio, la soledad..., y sin ponerme a hacer discretos discursos cerré tras de mí la puerta.....? Esta pasión lujuriosa, emocionalmente revivida lo induciría a revelar, sin darse él cuenta de ello, todos esos detalles de su infame acto, que no tienen relevancia alguna para identificar a Costanza o explicar el caso a los demás. Se podría pensar que manifiesta remordimiento al decir que a la madre de Costanza no se debe "culpar" por "lo que en ella parece manifiesto error y culpa conocida", porque él la "gozó contra su voluntadn: considerando el cinismo de este individuo, no resulta excesivo sugerir que también esta admisión, después de tantos años de total indiferencia, responde a algún motivo ulterior. ¿Tendrían algo que ver con ello los "treinta mil escudos de oro que [la] señora dejó para casar a su hija»? Ya otros lectores han sospechado tal posibilidad. "not surprisingly the caballero de Alcántara hurries up to accept Costanza into the family" ${ }^{23}$. Hasta en el momento de saber de la existencia de su hija, la preocupación venal es la que parece sobreponerse a cualquier otra emoción: "Recibí el dinero y las señales... y nos pusimos en camino" (945). Asimismo reveladora es su total impasibilidad durante el primer encuentro con la hija, quien, en cambio, "turbada y temblando",

${ }^{22}$ Casi siempre se mantiene lo contrario: R. EL SAFFAR, Novel to Romance: A study of Cervantes. Novelas ejemplares, Baltimore, 1974, 105.

${ }^{23}$ HerRero, «Emerging Realism, 56. 
hincada de rodillas ante él, «tomándole las manos, se las comienza a besar tiernamente, bañándolas con infinitas lágrimas..." (946).

Con referencia al tratamiento de ciertos temas fundamentales en la Comedia nueva, reflejo de creencias y prejuicios tradicionalmente muy enraizados, se ha observado: «se nos viene a dar por supuesto que es un proceder antinatural, inexplicable, sin causa lógica, producir ciertos valores y virtudes en un sujeto cuando no responden a los principios que diferencian las jerarquías sociales" ${ }^{24}$. El plebeyo se revelaría por los efectos característicos de "la carne», el noble por los del "espíritu" ${ }^{25}$. Cervantes se opone de modo categórico y a menudo a tal presunción, contestando que "la carne" y "el espíritu" están mezclados en toda persona, en proporciones diferentes, variables, de seguro, pero con independencia de la "sangre», del "nacimiento" en sí ${ }^{26}$. En nuestra obra -además del caso de Avendaño y del padre de Carriazo, ya discutidos-, se ilustra esta convicción, de modo muy ingenioso, en la absoluta insensibilidad de Carriazo por el amor de cualquier especie, a que prefiere el cínico trato picaresco; en su total desafecto a las actividades dignas, útiles, a las aspiraciones altas, virtuosas de la vida, a que prefiere «la libertad" de las almadrabas, con sus juegos, riñas, pullas, hurtos..., la gratificación del regateo por una cola de asno o del paseo por las calles «mirando bobas"; en su total "sordera" a las llamadas del «honor", cuyos "casos" resuelve, como gato arrinconado, por mero impulso defensivo o vengativo: «el aguador antiguo, despechado y lleno de cólera... le había pegado una docena de palos tales, que no le supieron bien [a Carriazo]. Apeóse en fin; pero con tan malas entrañas.... (929). En suma, esos instintos de honor o pundonor personal, de valentía heroica, espiritual, de amor ideal, apasionado, supuestamente innatos en la sangre "noble", no se manifiestan en ningún momento, en ningún aspecto de la conducta de $\mathrm{Ca}$ rriazo. Todo lo contrario, a pesar del tan privilegiado trato doméstico y social para su bienestar y placer, y de todos los cuidados y atenciones con que se atiende a su educación, en su casa, en Carriazo late "una inclinación picaresca" - radicalmente contradictoria a todos esos supuestos distintivos rasgos noblesque, a todas luces, es parte de su naturaleza idesde siempre! Cervantes lo pone muy de relieve: «sin forzarle a ello algún mal tra-

24 J. A. Maravall, Teatro y literatura en la sociedad barroca, Madrid, Seminarios y ediciones, 1972, 55.

$25 \mathrm{~J}$. MONTESINOS, «Algunas observaciones sobre la figura del donaire en el teatro de Lopew, Estudios sobre Lope, México, 1951, 45.

${ }^{26}$ Nuestros estudios mencionados en notas 7 y 21. 
tamiento que sus padres le hiciesen, isólo por su gusto y antojo! (921). Consecuentemente, esta "inclinación picaresca» puede quedar modificada, amansada, pero jamás por completo erradicada, lo cual precisamente parece sugerir el perenne temor de Carriazo a que alguien le reclame la cola, que se destaca al fin de la obra: temor al ridículo, pero, quizás, sobre todo, a su íntima convulsiva naturaleza (947) ${ }^{27}$. Puntualicemos, por fin, que si los atributos personales admirables no son privativos de las clases altas, por otra parte, los deplorables, como, por ejemplo, "la afición a Bacon, tampoco lo son de las clases bajas o de la picaresca, real o literaria, ini mucho menos! Así, "el rostro" que se le pone a uno "como si se le hubiesen jalbegado con vermellón y almagre... con alguna cosa que beba" (922), es un síntoma fisiológico que no discrimina entre clases sociales, y que, sugiere traviesamente el autor, muy precaria prueba constituiría de ser uno «bien nacido». Estas consideraciones no se contradicen por el hecho de que también otros "bien nacidos" van a las almadrabas, adonde sus padres "van o envían a buscarlos" (922), pues la posible reacción momentánea a específicas causas ambientales no excluye, por lo menos no en todos, la innata «inclinación picaresca».

El comportamiento de Costanza es impecable en todos los sentidos: con el mesonero y su mujer, a quienes quiere con ternura como si fuesen sus propios padres, es siempre respetuosa y obediente. A todos los huéspedes recibe con gentileza, pero a ninguno de ellos, aunque sean "señores de título» ${ }^{28}$, y muchos lo son, permite un trato íntimo. "No había ninguno que con verdad se pueda alabar que ella le haya dado lugar de decirle una palabra sola ni acompañada" (943), declara orgulloso el mesonero. Esto se ejemplifica del modo más concreto y revelador con la persecución amorosa y las extraordinarias ofertas de riqueza y estado de Avendaño (he aquí probablemente la función más importante de este personaje), a quien Costanza trata con cierta indulgencia y simpatía ("sin mostrar ira en los ojos»), pero a quien desanima como a todos los demás, al darse cuenta de sus intenciones: «andaba más recatada que solía" (939). En suma, muchísima gente la conoce y nadie "sabe de ella el menor desmán del mundo" (927), pese a que «la mala bestia del vulgo, por la mayor parte es mala, maldita y maldiciente" (939). Por el propósito de revelar la virtud de Costanza ante todo por medio de esta conducta tan

${ }^{27}$ Casalduero, «Diego se casa, tiene hijos, es feliz; pero vive temiendo. En Diego tenemos la inclinación al mal" (Sentido y forma de las novelas ejemplares, 200).

${ }^{28}$ Sobre el fenómeno de los jóvenes nobles «desgarrados" de casa, ver A. A. PARKER, Literature and the Delinquent, University of Edinburg, 1967, 14-16. 
recatada se explica que sus apariciones sean raras y aun más raras sus intervenciones verbales, $y$, consecuentemente, que se «delegue en quienes la rodean la revelación de sus condiciones físicas y morales" ${ }^{29}$. Es así impropio comparar a Costanza con otros personajes femeninos (Preciosa, por ejemplo), concluyendo que aquélla es menos interesante ${ }^{30}$, cuando no se distinga entre el tipo humano y su retrato artístico. La representación artística del tipo humano de Costanza es lograda y muy interesante. Todos piensan, pues, que "es la más honesta doncella que se sabe" y que "es maravilla que con estar en esta casa de tanto tráfago, y donde hay cada día gente nueva, y andan por todos los aposentos, no se sabe de ella el menor desmán del mundo" (927). ¡«es maravilla»!, coinciden, incrédulos, muchos lectores, destacando este hecho, además de los ya discutidos, como prueba de que en La ilustre fregona se afirma la virtud innata de la sangre noble, que se manifiesta de modo infalible, en cualquier circunstancia ${ }^{31}$. ¿Por qué parece tan increíble la conducta virtuosa, honesta, discreta de Costanza? El mesonero y su mujer la han educado bien, desde la infancia, enseñándole a leer, escribir, rezar, hacer labores domésticas,actividades en que está ocupada de continuo: «labrando está todo el día y rezando" (944). De seguro le han enseñado, sobre todo, a tratar con cordialidad hospitalaria, pero, a la vez, con suma prudencia y hasta recelo a toda la gente que viene al mesón. Además, siempre la protegen y vigilan con sumo cuidado, con "ojos de Argos", como se pone muy de relieve en el gracioso episodio de las coplas amorosas que Avendaño escribió en uel libro de la cebada», que cae en manos del mesonero: "dio con los versos, que, leídos, le turbaron y sobresaltaron. Fuese con ellos a su mujer, y antes que se los leyese, llamó a Costanza, y con grandes encarecimientos, mezclados con amenazas, le dijo le dijese si Tomás [Avendaño], el mozo de la cebada, la había dicho algún requiebro o alguna palabra descompuesta o que diese indicio de tenerla afición" (935). En suma, todo el comportamiento de Costanza refleja, de modo por completo verosímil, la moralidad, la discreción y la prudencia en que la educaron el mesonero y su mujer, "con tanto amor" ${ }^{32}$ y también, de modo muy

${ }^{29}$ A. M. BARRENECheA, "La ilustre fregona como ejemplo de estructura novelesca cervantinaw, Filología, 1961, 200.

${ }^{30}$ LowE, Cervantes: Two Novelas ejemplares, 69.

31 Ibid. nota 4.

32 Rodrfguez-Luis: «la perfecta virtud de ambas heroinas [Preciosa y Costanza], es también la consecuencia del extremo cuidado con el que las han guardado sus respectivos joyeros: gitana vieja y mesoneros" (Novedad de las novelas de Cervantes, 169). i«Tambiénn! 
importante, con aguda conciencia de la responsabilidad que les ha impuesto la peregrina al dejarles la niña: "quince años, un mes y cuatro días ha que aguardo a quien ha de venir por ella" (942). Pese a todos estos cuidados y prevenciones, Costanza cometería indiscreciones, si ella misma no estuviese determinada a no cometerlas: "madre, la mi madre / guardas me ponéis/ que si yo no me guardo/ no me guardaréis) (El celoso extremeño, 914) ${ }^{33}$. En estos versos se condensa una convicción cervantina, ilustrada en muchas situaciones de varias obras suyas, protagonizadas por mujeres virtuosas, castas, independientemente de su extracción social noble o plebeya. Así, la pureza moral de Costanza no tiene nada que ver con la "sangre noble" paterna. Este hecho se puntualiza con una poderosa, punzante ironía, haciéndosenos reparar en que Costanza no manifiesta ni la más mínima inclinación lujuriosa, que es, en cambio, tan avasalladora ien su padre! Y esto pese a que haya pasado toda su vida en una posada, en que la tentación acecha de continuo, como lo atestiguan la Argüello y otras fregonas ${ }^{34}$. Por su propia determinación de ser virtuosa, Costanza puede serlo en cualquier lugar, corte o mesón, por lo cual resulta irónicamente innecesaria la intención del corregidor de «llevarla» cuanto antes de «aquella posada" a "un monasterio" (943) ${ }^{35}$. Penosamente irónico es también el hecho de que todos estos nobles se afanen tanto en reconocer "la señal verdadera" por medio de fragmentos de cadenas y pergaminos, mientras tan despreocupados están de la señal más genuina de Costanza, que es su "virtud», y del lazo más formidablemente unitivo entre la gente, que son sus corazones amantes.

En La ilustre fregona ocurren "transformaciones dignas de anteponerse a las del narigudo poeta" (929). Inspirándose en el tema principal de las Metamorfosis de Ovidio: «Nihil est toto, quod perstet, in orbe" ${ }^{36}$, Cervantes lo ilustra en situaciones y problemas palpitantes de su propio tiempo, derivando de ello la ejemplaridad

${ }^{33}$ CASAlduero: «Ella misma tiene la llave» (Sentido y forma de las novelas ejemplares, 202).

34 Sobre las funciones lamentables de las fregonas de posadas ver el estudio de M. JolY, «Para una reinterpretación de La ilustre fregona: Ensayo de tipología cervantinaw, Beiträge zu Texte des Siglos de Oro, Wiesbaden, 1983, 103-116.

${ }^{35} \mathrm{Si}$ Costanza uparecía hermosa con los [vestidos] de labradora, con los cortesanos parecía cosa del cielo; tan bien le cuadraban que daban a entender, que desde que nació había sido señora y usado los mejores trajes que el uso trae consigow (356). Tampoco esta observación contradice nuestra tesis, pues no es a la «sangre" sino al modo de ser de Costanza a lo que se atribuye su aspecto de gran useñoraw.

${ }^{36}$ Libro XV, verso 177. 
ideológica, moral de su obra: En el mundo no hay nada inmutable, todo cambia de continuo. Frente a este axioma cósmico se le revela absurda la contención de la superioridad innata de la "sangre noble", invariable, constante, heredada de generación en generación. (Como se ha visto, dejando aparte el dudoso quilate de la "nobleza" del padre de Carriazo, su hijo manifiesta inclinaciones individuales distintas, y, a su vez, los hijos de éste inclinaciones suyas propias, según se sugiere al fin. 947). Lo que no cambia, desde siempre, es la sangre humana, herencia imparcial de todos los hombres, en todas sus manifestaciones características, distintamente reconocible bajo cualquier envoltura o disfraz con que se encubra a través de la historia. Esta se desarrolla como una maravillosamente dinámica, rica variación sobre el tema perenne que es esta sangre humana. Momentos notables de esta historia ocurren por "los casos de Fortuna", en que debe incluirse también lo accidental del nacimiento "noble" ${ }^{37}$. No cabe duda, sin embargo, que en todas las obras cervantinas se dignifica sólo el acto o la vida que es reflejo directo de la aspiración y del esfuerzo del Individuo, del Hombre, del Hijo de la Naturaleza, benévola y perversa a la vez. Consiste en esto, creemos, la fundamental filosofía existencial de Cervantes ${ }^{38}$.

El motivo de la "transformación", que se articula con tan importantes implicaciones sociales y humanas, es también «a significant device for the structure of this novella" ${ }^{39}$. Es, en efecto, su recurso literario primordial: precisamente por medio de él se crea la acción tan varia y rápida, sin zonas estáticas; los continuos cambios de todo orden; el movimiento fluido, en múltiples direcciones, en distintos planos..., cuya complejidad, muy sugerentemente, se ha intentado representar ya muchas veces con

${ }^{37}$ Nuestros estudios, notas 7 y 21 . Algunas observaciones interesantes sobre este problema en A. WEBER, "La ilustre fregona and the Barriers of Castew, Papers on Language and Literature, vol. 15, 1979.

${ }^{38}$ Cervantes no menosprecia en absoluto las influencias externas en toda vida humana: el azar, la casualidad, el «destino», la «Fortuna», buena o mala, etc., pero cuando las introduce es, ante todo, con el propósito de perfilar mejor el carácter del personaje que con ellos se encuentra. R. EL SAFfar, entre otros críticos, no parece tener en cuenta este hecho tan fundamental para el aprecio de la estructura narrativa. Creer que en cualquier obra cervantina «Fortune, rather than character, tiene "the dominant role in plot development" (From Novel Romance, 86), constituye, para nosotros, un grave error en la comprensión del pensamiento de Cervantes.

${ }^{39}$ K. L. Selig, "The Metamorphosis of the La ilustre fregonan, Filologia y critica hispánica, Madrid, 1969, 116. 
toda clase de esquemas gráficos, y describir o definir observaciones y expresiones críticas muy reveladoras en sí: "conjunciones y disyunciones [de varios elementos]...; movimiento entre dos términos...; sucesión de círculos concéntricos o de cuadrados insertos...; desplazamientos constantes...; discontinuidad y confluencia...; organización secuencial de la intriga...; visión del mundo como multiplicidad...; varios niveles de enunciación engastados...; oposición de los personajes y de su trayectoria..; entramado de relaciones referenciales e intertextuales...; trayectoria lineal e inversa del relato...; espacios que se desdoblan...; etc. ${ }^{40}$. Todas estas observaciones acertadas, perspicaces, $\mathrm{y}$, esencialmente, constantes con las añejas sobre la «errabundez y movilidad de los protagonistas", sobre sus "muchos caminos" como «un devenir, un movimiento hacia la consumación o una destrucción o una revelación", y su kespacio mítico como viaje», etc. ${ }^{41}$, traducen, de manera precisa, aunque inconsciente, la metáfora más englobadora y poética del tema central de las Metamorfosis de Ovidio: «sed ut unda inpellitur unda / urgeturque prior veniente urgetque priorem, / tempora sic fugiunt pariter pariterque sequuntur / et nova sunt semper" ${ }^{42}$. Buen conocedor de las obras ovidianas, según lo sugieren sus citas de éstas ${ }^{43}$, a Cervantes de seguro llamaría la atención una imagen tan esencial para el debido aprecio de las Metamorfosis, y itan hermosa! para él, contemplador siempre fascinado de las olas del mar y de los ríos, y autor de muy felices referencias literarias a ellas.

¡La vida humana como olas en su incesante movimiento y mutuo empuje, en su inexorable curso hacia horizontes incógnitos, misteriosos! ¡Olas de dimensiones, fuerzas, formas, matices... variables a cada instante, siempre nuevas, $y$, a la vez, de algún modo, también siempre viejas; olas en un eterno hacerse, deshacerse, rehacerse, ¡transformarse!, que es el de todo el Universo!

${ }^{40}$ Los términos citados se encuentran en los estudios sobre La ilustre fregona de A. M. MAestro, "Conjunciones y disyunciones en La ilustre fregonai; J. PAULINO, «El espacio narrativo en La ilustre fregona, cuatro cuartos y una colaw; M. DÉBAX, "Ser y parecer"; M. EzouerRo, "Tres por dos son seis"; M. RAMOND, "Yo soy La ilustre fregona o la simbolización de un delirion; C. СНAUchadIS, «Los caballeros pícaros: contexto e intertexto en La ilustre fregonas; J. ALSINA, «Algunos esquemas narrativos y semánticos en La ilustre fregonas, en Lenguaje, ideología y organización textual en las Novelas ejemplares, Actas del coloquio celebrado en la Facultad de filología de la Universidad Complutense en mayo de 1982. Coordinador: J. J. de Bustos Tovar, Madrid, Le Mirail, 1983.

41 W. PABST, La novela corta en la teoría y en la creación literaria, Madrid, Gredos, 1978, p. 228; P. DuNN, «Las Novelas ejemplares», Suma cervantina, Támesis, 1973, 94.

42 Libro XV, versos 181-4.

${ }^{43}$ Ver en la ed. de A. Valbuena Prat, pp. 98, 577, 752, 882, 1033, 1036, 1348 , etc. 
Esta inspiradora metáfora, a que da cómoda cabida el muy amplio marco de la obra ovidiana, se reincorpora itan atrevidamente! en el estrecho, restrictivo espacio de una novela corta, hecho en sí muy significativo, pero nada sorprendente, al tomarse en cuenta la característica inclinación innovadora de Cervantes. En efecto, La ilustre fregona parece responder, primordialmente, al propósito de proponer tanto en lo ideológico (con su tema actualizado y tan significativo) como en lo literario (con la adaptación tan ingeniosa y original de la metáfora inspiradora) una posibilidad novelística de recrear temas clásicos, para provecho moral, cívico, y para deleite artístico del lector contemporáneo. En tal propósito ideal, ejemplar viene implícita la crítica de las muchas imitaciones y adaptaciones insensatas, temática y estéticamente, como lo ilustra también el primo ¡«humanistan! del Quijote, quien, entre otras obras estrambóticas, se propone componer también "Metamorfosis u Ovidio español, de invención nueva y rara, porque en él, imitando a Ovidio a lo burlesco, pintó quien fue la Giralda de Sevilla, etc." (1348).

Ofrecer una imagen precisa, pormenorizada, completa de todos los movimientos y aspectos de las olas de La ilustre fregona, sería casi tan imposible como emprender tal tarea con las de un brioso río montañés. Se señalan así sólo algunas de ellas, con la intención principal de destacar el fenómeno y su ingeniosa realización artística, demostrando así también el error de pensar que esta novela está "escrita sin plan" ${ }^{44}$.

Como ola de súbito arrancada por invisibles fuerzas internas del seno de una masa de agua remolona, surcando briosa hacia una vorágine tragadora, Carriazo "se desgarr[a] de la casa de sus padres y se [va] por ese mundo adelante», entregándose alegremente a la ventura de los caminos abiertos, de las metas fascinantes por desconocidas, atraído irresistiblemente, a su tiempo, al babilónico torbellino de las almadrabas de Zahara. En uno de sus impetuosos movimientos arrastra tras su corriente otra ola, de flujo ya paralelo -Avendaño-, entremezclándose las dos de inmediato e impeliéndose mutuamente, "como burlando con alegres veras" (El viaje del Parnaso, 78) 45: "y ellos volvieron las riendas..., vistiéronse a lo payo... Puestos, pues, a la ligera... se pusieron en camino... contentos y alegres" (924). Empuje repen-

44 Rodríguez-Luis, Novedad de las novelas de Cervantes, 120. A menudo se opina que esta novela no tiene unidad, que tiene la acción dispersa, episodios, personajes, detalles irrelevantes, etc.

${ }^{45}$ Recordamos algunos versos de esta obra, referidos al mar, al río, al viaje, etc., pero, claro está, se podrían encontrar muchísimas otras referencias literarias de este tipo en otas obras cervantinas, en prosa y verso. 
tino, impetuoso de otra corriente - noticia de la belleza de Costanza-, áspero cambio de rumbo, hacia un efervescente torbellino, alrededor de cuyo centro imantado ya giran bulliciosas e impotentes muchas olas y olitas, a las cuales se une, igualmente atraída, otra - Avendaño-, mientras una poderosa fuerza centrífuga se lleva la ola compañera - Carriazo- a entremezclarse con las aguas periféricas, en otra órbita tormentosa y convulsa: el mundo de aguadores, mozos de mulas, pícaros, fregonas. Brote violento en las aguas ya revueltas - aparición de los padres de Carriazo y Avendaño en la posada-: olas atávicas, siempre contenidas, en parte, también en las desprendidas, de curso propio. Entre las olas grandes, impetuosas, fragorosas, "presuntuosas, en visitar las nubes de contino, y aun de tocar el cielo codiciosas (El viaje del Parnaso, 77), las pequeñas, mansas, casi imperceptibles, a menudo impelidas "a tocar de la ribera los umbrales" (Ibid, 68): el ayo descartado, de quien ya "no dice nada el autor", después de ponerle "a caballo" para hacerle volver a Burgos (924); muy a menudo, de brevísimo recorrido visible, pero de un curso pasado o futuro sugerido o, a veces, de una meta final adivinable: "el dueño [del asno vendido a Carriazo] había ganado con él en menos tiempo de un año, después de haberse sustentado a él y al asno honradamente, dos pares de vestidos y más aquellos diez y seis ducados, con que pensaba volver a su tierra donde le tenían concertado un casamiento con una media parienta suya" (938). Poco después, al perder todo el dinero en el juego, se desbaratan todos estos bellos proyectos de felicidad: «se arrojó en el suelo y comenzó a darse de calabazadas por la tierra..." (939). El lector imagina la potencial tragedia de varias familias. Es el típico modo cervantino de contemplar aún a sus más transitorios, menudos personajes novelísticos en alguna significativa dimensión humana, aunque sólo con brevísima ojeada. Sin embargo, aún tales consideraciones, a primera vista desviadas del asunto central, se revelan, a la postre, relevantes; en nuestro caso, constituyen una ocasión para que Carriazo demuestre su "generosidad". La relevancia novelística de algunos personajes, como la de Argüello, que, además de sus propias frustaciones intimas ${ }^{46}$, contribuye a enfocar el carácter de Costanza, es bastante evidente; mientras la de otros es más incierta, pero, en todos los casos sí se descubre, de un modo u otro ${ }^{47}$. Invitan a una breve mención particular las "personas... de tal calidad», a quienes alude el mesonero, "de socarrón", para sacar a Carriazo

46 A. M. BARREnecheA, «La ilustre fregona como ejemplo de estructura novelesca cervantinan, 200.

47 Ver nota 44. 
de la cárcel: «y como ésta pida a su hija, que sí pedirá, hable a la hermana del fraile que hable a su hermano que hable al confesor, y el confesor a la monja, y la monja..." (930). Oleaje juguetón, que de un modo cómico, asimismo simboliza la constante, intensa interdependencia de todos los personajes, principales, secundarios, accidentales, en la novela, reflejo fidedigno de las relaciones humanas.

Oleajes en continuo «influjo y reflujo" (El viaje del Parnaso, 82) en el vasto mar, multiformes y multicolores con miles de matices, "cerúleos y canos" (El viaje del Parnaso, 87), límpidos, turbios, grisáceos, verdosos, lejanos, claros, borrosos, aparenciales, evanescentes...: Fantástica gama de lenguajes: cortesano, retórico, dialectal, folklórico, refranesco, poético, prosaico, humorístico, burlesco, rufianesco, íntimo, oficial..., para mencionar sólo algunos de los que en La ilustre fregona se entrecruzan y se fecundan mutuamente con tanto fervor ${ }^{48}$. Esto se aprecia con muy particular placer en la gran riqueza de imágenes derivadas de las más diversas experiencias humanas, a veces conflictivas: "¿Y quién diablos te enseñó a cantar a una fregona cosas de esferas y de cielos, llamándola lunes y martes... Dijérala... que es tiesa como su espárrago, entonada como un plumaje, blanca como una leche, honesta como un fraile novicio, melindrosa y zahareña como una mula de alquiler, y más dura que un pedazo de argamasa..." (934). En éste y otros casos en la novela, en que la palabra o la imagen genera de repente, de modos muy variados, múltiples nuevos sentidos, implicaciones, sugerencias, impresiones, etc., se tiene la distinta sensación de un espectacular estallido de fuegos artificiales $o$, consistente con nuestra metáfora, de un brioso brote de agua, desparramándose en el aire en mil gotitas iridiscentes.

"En fin llegamos donde el mar se extiende y ensancha..." ( $E l$ viaje del Parnaso, 90): placentera sensación del viaje felizmente acabado, como el de las turbulentas olas de nuestra novela, desembocando en un mar pacífico, luminoso: «quedaron todos contentos, alegres y satisfechos con los matrimonios contraídos». Del suyo Carriazo tiene «ni más ni menos,... tres hijos, que, sin tomar el estilo del padre ni acordarse si hay almadrabas en el mundo, hoy están todos estudiando en Salamanca» (947). ¡Por lo menos por el momento! También Avendaño estudiaba en Salamanca antes de huir de casa. "Turbóse en esto el líquido elemento, de nuevo renovóse la tormenta..." (ibid, 89): No se preanuncia con seguridad tal futuro para los hijos de Carriazo, pero tampoco se

48 Parece intuir el problema W. H. ClamurRo, inspirado en Bajtin, kIdentity, Discourse, and Social Order in La ilustre fregonas, Cervantes, 7, 1987, 39-56. 
lo excluye por completo: el ser humano es imprevisible y su vida sin cauces predeterminados, i"se hace camino al andar"! Bajo la superficie aparentemente plácida del final hay posibles turbulencias a punto de explotar con gran vehemencia, para recomenzarlo todo de nuevo: iNNihil est toto, quod perstet, in orbe»!

A menudo se trata de distinguir la voz de Cervantes de la del otro "autor" (924) y de las de otros narradores y "poetas del dorado Tajo" (947), lo que, muy significativamente, siempre resulta arduo ${ }^{49}$. Así lo desea Cervantes mismo, quien, al proponer las olas como metáfora de la humanidad, es consciente de que él, como ser humano y como escritor, debe aparecer fundido con ellas, jola entre otras olas de inmenso mar que es la vida! ${ }^{50}$.

STANISLAV ZIMIC

University of Texas, Austin

49 Algunas observaciones sobre esto, sugestivas de lo problemático a que aludimos, en R. El SAFFaR, From Novel to Romance, 107-8.

${ }^{50}$ Se ha observado repetidas veces que la kilustre fregonaw constituye un axymorón. Para nosotros, se trata más bien de una simbiosis natural de elementos contrarios, presentes en toda persona: A nivel de símbolo. 